Tropical Journal of Pharmaceutical Research September 2019; 18 (9): 1977-1983

ISSN: 1596-5996 (print); 1596-9827 (electronic)

(1) Pharmacotherapy Group, Faculty of Pharmacy, University of Benin, Benin City, 300001 Nigeria.

\title{
Biodistribution and pharmacokinetic studies on topically- delivered technetium-99m-labeled 5-FU nanogel formulation for management of pre-cancerous skin lesions
}

\author{
R Rajagopalan ${ }^{1 *}$, Sanjay K Jain ${ }^{2}$, Ankur Kaul' ${ }^{3}$, Piyush Trivedi ${ }^{1}$ \\ ${ }^{1}$ Department of Pharmaceutics, School of Pharmaceutical Sciences, Rajiv Gandhi Technological University, Bhopal (M.P), \\ ${ }^{2}$ Department of Pharmaceutics, Dr Harisingh Gour University, Sagar (M.P), ${ }^{3}$ Division of Cyclotron \& Radiopharmaceutical \\ Sciences, Institute of Nuclear Medicine and Allied Sciences (INMAS), DRDO, New Delhi, India
}

*For correspondence: Email: rajagopalan10@gmail.com; Tel: +91-9179626663

Sent for review: 17 April 2019

Revised accepted: 19 August 2019

\begin{abstract}
Purpose: To prepare technetium-99m ${ }^{99 m-T C)}$-labelled nanogel loaded with 5-fluorouracil (5-FU) containing synthesized gallic acid-stearylamine (GA-SA) conjugate in order to reduce its systemic toxicity and provide site-specific delivery to skin lesions.

Methods: Lipid nanocarrier-based $1 \%$ (w/w) 5-FU nanogel containing GA-SA conjugate was successfully formulated. Parameters that included $\mathrm{pH}$, viscosity and entrapment efficiency were measured. Furthermore, $1 \%(w / w) 5-F U$ nanogel and $1 \%(w / w)$ 5-FU commercial formulations were radiolabelled with ${ }^{99 m-}$ TC. The radiolabelled ${ }^{99 m-}$ TC-5-FU nanogel and commercial formulations were subjected to successive preclinical assessments with respect to radiochemical stability, biodistribution, and gamma scintigraphy in BALB/c mice, and pharmacokinetic studies in New Zealand albino rabbits.

Results: The entrapment efficiency of 5-FU in the nanogel preparation was $82.12 \pm 1.2 \%$. The 5-FU nanogel formulation exhibited excellent radiolabelling efficiency (> $93 \%$ ) and high stability. Skin/blood localization ratios of 274.93 and 167.89 were obtained for topical radiolabelled drug-loaded 5-FU nanogel formulation and 5-FU commercial formulation, respectively, after $1 \mathrm{~h}$ of administration. Gamma scintigraphy and biodistribution studies showed that topically administered ${ }^{99 m-}{ }^{9} \mathrm{~T}-5-\mathrm{FU}$ nanogel was distributed mostly in skin, when compared to marketed 5-FU formulation. Pharmacokinetic studies revealed low maximum activity in the blood $\left(C_{\max }=34.20 \mu \mathrm{g} / \mathrm{mL}\right)$, with low intensity $(A \cup C)$ for topically administered ${ }^{99 m-T C-5-F U}$ nanogel formulation.

Conclusion: 5-FU nanogel enhances specific delivery of 5-FU at targeted sites and decreases its toxicity in tissues distant from the site of application. The results suggest that nanogel loaded with 5-FU containing synthesized GA-SA conjugate is a novel effective approach for the treatment of skin lesions.
\end{abstract}

Keywords: 5-Fluorouracil, Skin lesions, ${ }^{99 m}$ Technetium, Biodistribution, Pharmacokinetics, Gamma scintigraphy

This is an Open Access article that uses a fund-ing model which does not charge readers or their institutions for access and distributed under the terms of the Creative Commons Attribution License (http://creativecommons.org/licenses/by/4.0) and the Budapest Open Access Initiative (http://www.budapestopenaccessinitiative.org/read), which permit unrestricted use, distribution, and reproduction in any medium, provided the original work is properly credited.

Tropical Journal of Pharmaceutical Research is indexed by Science Citation Index (SciSearch), Scopus, International Pharmaceutical Abstract, Chemical Abstracts, Embase, Index Copernicus, EBSCO, African Index Medicus, JournalSeek, Journal Citation Reports/Science Edition, Directory of Open Access Journals (DOAJ), African Journal Online, Bioline International, Open-J-Gate and Pharmacy Abstracts

\section{INTRODUCTION}

Actinic keratosis (AK) is a precancerous disease which occurs in the epidermal layer of the skin.
The disease which is also known as solar keratosis, occurs mostly in individuals who are chronically exposed to UV radiation [1]. It manifests as red scaly patches on the skin which 
vary in size from 1 to $20 \mathrm{~mm}$ [2]. Actinic keratosis lesions indicate the early stage of non-melanoma skin cancer. Lesions may occur singly or in multiples, and may vary in diameter from 0.1 to $2.5 \mathrm{~cm}$. Usually, AKs are considered as lesions with low potential for aggressive malignancy, which subsequently develop higher potential for spontaneous regression. An invasive AK has the potential to develop into the squamous cell carcinoma (SCC), a serious type of skin cancer [3].

Lipids present in the skin contribute to its barrier properties, and may serve as rate limiting membrane barrier for systematic absorption of active moieties. Lipid vesicles are non-toxic penetration enhancers due to their amphiphilic nature [4]. In addition, vesicles which are rich in lipids are used to carry substantial quantities of drugs across the skin through enhancement of cutaneous retention and drug permeation [5]. Nanogels are nanosized particles formed via chemically crosslinked polymer networks that swell in appropriate solvents. They have the capacity to form complexes with various DNAs, proteins and drugs, and they are also used to coat surfaces of liposomes and solid surfaces, including cells $[6,7]$. In contrast to other transdermal delivery agents such as creams and ointments, nanogels act as excellent carriers with stable and controlled drug release kinetics, with lower side effects [8]. Due to their tiny volumes, they have the ability to penetrate tissues through transcellular or paracellular pathways [9].

Technetium-99m ( ${ }^{99 m-\mathrm{Tc}}$ ) is the most widespread radionuclide due to its versatile chemistry, cost effectiveness, low radiation dose, near-ideal energy (140 keV), short half-life (6 h), and ideal nuclear medicine imaging properties [10,11]. A previous study showed that combination therapy using 5-FU/GA-SA conjugate at a ratio of $1: 1$ (1: $10 \mu \mathrm{g} / \mathrm{mL}$ ) provided synergistic cytotoxicity in A431 skin cancer cells [12]. In continuation of the study, the present work focused on the preparation and evaluation of 5-FU nanogel containing GA-SA conjugate formulation to potentiate site-specific drug delivery and reduce systemic toxicity in the treatment of skin lesions.

\section{EXPERIMENTAL}

\section{Chemicals}

5-Fluorouracil was purchased from Ranbaxy Industries Ltd. Sodium cholate was obtained from Sigma Aldrich Pvt Ltd, Bangalore, India. Soya lecithin was purchased from Acros Organics (USA). Triethanolamine (98\%), methyl paraben, propyl paraben and propylene glycol were products of Central Drug House Pvt Ltd, New Delhi, India, while Carbopol 934 were bought from Himedia Pvt. Ltd, Mumbai, India.

\section{Animals}

BALB/c mice weighing 20 - $25 \mathrm{~g}$ were used for biodistribution studies, while New Zealand albino rabbits weighing 2 - $3 \mathrm{~kg}$ were used for pharmacokinetics studies. All animal experiments were followed by International regulations of AAALAC [13] (Assessment and Accreditation of Laboratory Animal Care International). The experimental protocols were approved by the Institutional Animal Ethics Committee of Institute of Nuclear Medicine and Allied Sciences, New Delhi, India (approval no. INM/IAEC/16/03 INMAS).

\section{Formulation of lipid carrier based 5-FU nanogel with GA-SA conjugate}

Gallic acid (GA)/stearylamine (SA) conjugate was prepared using the method outlined in a previous report [12] Soya lecithin (lipid, $9.5 \mathrm{~g}$ ), sodium cholate (surfactant, $0.5 \mathrm{~g}$ ) and GA-SA conjugate $(10 \mathrm{~g})$ were put in a round bottom flask and dissolved with chloroform: methanol mixture (3 : $1 \mathrm{v} / \mathrm{v})$. The organic solvent was removed using a rotary evaporator (Model Buchi Rotavapor R-300 India) to form a lipid film on the inner side of the flask. Residual drops of organic solvent were removed using a vacuum oven (Model Hmg, India). The lipid film was hydrated with sufficient quantity of $5-\mathrm{FU}[1 \%(\mathrm{w} / \mathrm{v})$ solution in phosphate buffer saline, $\mathrm{pH}$ 7.4] to form lipid carrier dispersion. Then, it was probe-sonicated with Model VCX 500 (Sonics, USA) for $5 \mathrm{~min}$ at $30 \%$ output frequency to form the lipid nanocarrier dispersion.

\section{Incorporation of the prepared 5-FU lipid nanocarrier dispersion system in carbopol gel base}

5-Fluoro uracil (5-FU) nanogel (liposome bearing 5-FU gel) formulations were prepared by adding the fine 5-FU lipid nanocarrier dispersion system to carbopol 934 polymer (3.5\%). The polymer was gradually mixed with distilled water. It was hydrated and allowed to swell for $5 \mathrm{~h}$. The medium $\mathrm{pH}$ was adjusted to 5.5 using triethanolamine (98\%), followed by agitation for $1 \mathrm{~h}$ with mechanical stirring until a transparent gel was formed. Methyl paraben $(0.1 \%)$ and propyl paraben $(0.01 \%)$ were mixed in propylene glycol and added as preservatives. The gel was allowed to equilibrate for at least $24 \mathrm{~h}$ at room temperature. Then, the 5-FU lipid nanocarrier dispersion system was added to the polymer gel, 
and continuously stirred until a uniform nanogel was attained.

Assessment of entrapment efficiency,
viscosity and pH

The DVII + Pro Brookfield viscometer were used to measure viscosity. It contains a tiny adapter for placing the sample (Spindal SC4-18 and 13-R chamber) so as to determine the viscosity values of 5-FU nanogel at percentage torque values of 10 - 100 (Brookfield Engineering Laboratories, USA). The $\mathrm{pH}$ of 5 -FU nanogel was directly measured at room temperature in samples using $\mathrm{pH}$ meter (Thermo Orion, USA). The entrapment efficiency of 5-FU nanogel was estimated after separating it from the entrapped drug. In this process, $100 \mathrm{mg}$ of 5-FU nanogel preparation was hydrated with $10 \mathrm{~mL}$ of $0.9 \%$ sodium chloride: methanol mixture (8: $2 \mathrm{w} / \mathrm{v})$, and shaken manually for $5 \mathrm{~min}$. The sample was centrifuged for $30 \mathrm{~min}$ at $5000 \mathrm{rpm}$ to separate the unentrapped drug, and the clear supernatant was gently separated from the sample. The unentrapped drug solution (1 $\mathrm{mL})$ was diluted using $10 \mathrm{~mL}$ of saline: methanol solvent, and its UV-absorbance was measured. The resultant sediment was resuspended in $0.2 \%$ Triton $\mathrm{x}-100$ (1 $\mathrm{mL})$, and the UV absorbance of the suspension was measured. The total amount of drug comprised the drug present in both sediment and supernatant [14]. The drug content was analysed using UV-1700 spectrophotometer (Shimadzu, India). The entrapment efficiency (EE) was computed as shown in Eq 1.

$C(\%)=A / B \times 100$

where $A$ is the quantity of drug deposited as sediment, $B$ is the overall quantity of $5-\mathrm{FU}$ added, and $C$ is the 5-FU encapsulation efficiency.

\section{Preparation of radiolabelled drug formula- tions}

Direct-labelling technique with ${ }^{99 m}$-Tc was used for radiolabelling of 5-FU nanogel formulation and marketed formulation [15,16]. Stannous chloride dihydrate $(100 \mu \mathrm{g})$ was added to $100 \mu \mathrm{L}$ of $0.01 \mathrm{M} \mathrm{HCl}$. Then, $0.5 \mathrm{~mL}$ of the resultant solution was mixed separately with 5-FU nanogel and 5-FU marketed formulation. The $\mathrm{pH}$ was adjusted to 6.5 using $0.5 \mathrm{M} \mathrm{NaHCO}_{3}$. Then, ${ }^{99 m}$ Tc was added under sterile conditions, with constant stirring, and the mixture was kept warm in an incubator for $10 \mathrm{~min}$ at ambient temperature.

\section{Radiochemical stability studies on ${ }^{99 m-}$ Tc 5-FU nanogel}

Radiolabelling efficiency was measured using instant thin layer chromatography (ITLC)- silica gel-coated fibre plates (ITLC-SG), with $100 \%$ acetone as solvent. Approximately $2-3 \mu \mathrm{L}$ of radiolabelled compound was applied at the bottom of the plate, and was developed in acetone. Furthermore, the strips were cut into small pieces of size $0.5 \mathrm{~cm}$. The gamma count of each piece was measured using Caprac- $R$ scintillation well counter, and the labelling efficiency values of 5-FU nanogel and marketed 5-FU formulation were calculated [17]. The stability of these two formulations were evaluated for $24 \mathrm{~h}$ at various time periods. The percentage labelling efficiency was calculated as shown in Eq 2:

$E=100-D$

where $D$ is the percentage free ${ }^{99 \mathrm{~m}-} \mathrm{Tc}$, and $E$ is the percentage labelling efficiency

\section{Biodistribution studies}

Two groups of BALB/c mice (groups 1 and 2; 3 mice per group) were used. The mice were allowed ad libitum access to pellet diet and drinking water. All mice were shaved at the back $24 \mathrm{~h}$ before starting the experiments. Group 1 mice were administered ${ }^{99 m}-T c-5-F U$ nanogel, while group 2 mice were given $99 \mathrm{~m}-\mathrm{Tc}-5-\mathrm{FU}$ marketed formulation. The two treatments were applied topically, each at a dose of $500 \mu \mathrm{L}$. At time intervals of $60,120,240$ and $1440 \mathrm{~min}$, blood samples were collected from each animal through cardiac puncture. Simultaneously, tissue samples were taken from the skin, heart, kidney, lung, bladder, liver, stomach and intestine. The tissues were washed twice using $0.9 \% \mathrm{NaCl}$ to rid them of adhering and unwanted tissue, and then weighed. The radioactivity in each tissue was measured using Caprac- $R$ well-type gamma scintillation counter. The results were calculated in terms of percentage of applied dose per gram tissue using Eq 3 [18].

$I=\{(F / G) / H\} \times 100$

where $F$ is the count of the sample, $G$ is the weight of the sample, $H$ is the total count administrated, and $I$ is the percentage of administered dose per gram of tissue.

\section{Pharmacokinetic studies}

Three healthy albino New Zealand rabbits were used for this aspect of the study. Radiolabelled 
${ }^{99 \mathrm{~m}} \mathrm{TC}-5-\mathrm{FU}$ nanogel and 5-FU marketed formulations were administered topically $(0.5$ $\mathrm{mL})$. At different time intervals $(0.25,0.5,1,2,3$, 4, 5 and $24 \mathrm{~h}$ ), blood samples were collected in pre-weighed tubes and subjected to radioactivity count. The pharmacokinetic parameters (PK) of the radiolabelled formulations were obtained with PK solver 2.0 software.

\section{Gamma scintigraphy imaging}

The radiolabelled formulation of ${ }^{99 m}$-Tc- 5-FU nanogel and ${ }^{99 m}$-TC-5-FU marketed formulation were applied topically at a dose of $500 \mu \mathrm{L}$ on 2 $\mathrm{cm}^{2}$ of the shaved dorsal area of each animal. Scintigraphic imaging was achieved using single photon emission computerized tomography (Diacam, LC 75-005, Siemens AG; Erlanger, Germany) at intervals of 2,4 and $24 \mathrm{~h}$ postadministration.

\section{Statistical analysis}

Data are expressed as mean \pm SD (standard deviation). Statistical analysis was carried out using Statistical Package for Social Sciences version 16.0 software (SPSS). $P<0.05$ was set as statistically significant.

\section{RESULTS}

\section{Physicochemical properties of 5-FU nanogel formulation}

The viscosity, $\mathrm{pH}$ and percentage entrapment efficiency of 5-FU nanogel formulation are given in Table 1.

Table 1: Physicochemical properties of 5-FU nanogel formulation

\begin{tabular}{lc}
\hline Parameter & $\begin{array}{l}\text { 5-FU nanogel } \\
\text { formulation }\end{array}$ \\
\hline Viscosity $(\mathrm{cp})$ & $2800.9 \pm 9.40$ \\
$\mathrm{pH}$ & $6.5 \pm 0.01$ \\
Entrapment of 5-FU (\%) & $82.12 \pm 1.2$ \\
\hline \multicolumn{2}{l}{ Values are expressed as mean $\pm \mathrm{SD}(\mathrm{n}=3)$}
\end{tabular}

\section{Radiochemical stability of ${ }^{99 \mathrm{~m}} \mathrm{Tc}$ nanogel}

The radiolabelling efficiencies of ${ }^{99 m}$-Tc-5-FU nanogel and 5-FU marketed formulations were higher than $93 \%$, as shown in Figure 1.

\section{Biodistribution}

The levels of radioactivity at various time points in heart, blood, intestine lung, bladder, liver, stomach, kidney and skin tissues are presented in Figures $2-3$. The skin/blood ratio of the ${ }^{99 m}$.
Tc-5-FU nanogel and ${ }^{99 m}$-Tc-5-FU marketed formulations are shown in Table 2.

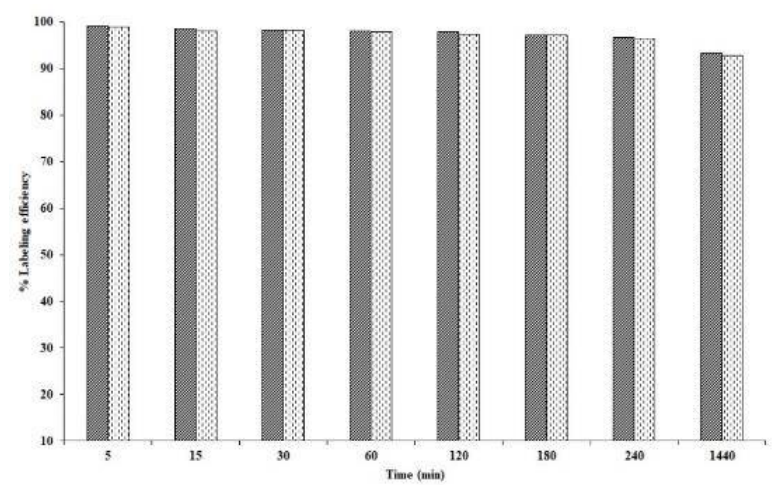

Figure 1: Radiolabelling efficiency and stability at room temperature up to $24 \mathrm{~h}$. $\mathbb{Z}^{-99 \mathrm{~m}} \mathrm{Tc}$ labelled 5-FU nanogel; ㄴ. ${ }^{99 m-T c ~ l a b e l l e d ~ m a r k e t e d ~ f o r m u l a t i o n ~}$

Table 2: Skin/blood ratio of the labelled formulations of $5-\mathrm{FU}$ at various time intervals

\begin{tabular}{llcccc}
\hline $\begin{array}{l}\text { Formula- } \\
\text { tion }\end{array}$ & $\begin{array}{l}\text { Organ } \\
\text { /tissue }\end{array}$ & $\mathbf{6 0} \mathbf{~ m i n}$ & $\begin{array}{c}\mathbf{1 2 0} \\
\mathbf{m i n}\end{array}$ & $\begin{array}{c}\mathbf{2 4 0} \\
\mathbf{m i n}\end{array}$ & $\mathbf{1 4 4 0} \mathbf{~ \mathbf { i n }}$ \\
\hline Nanogel & Skin/blood & 274.93 & 259.48 & 293.80 & 1165.20 \\
Marketed & Skin/blood & 167.89 & 145.33 & 141.83 & 144.36 \\
\hline
\end{tabular}

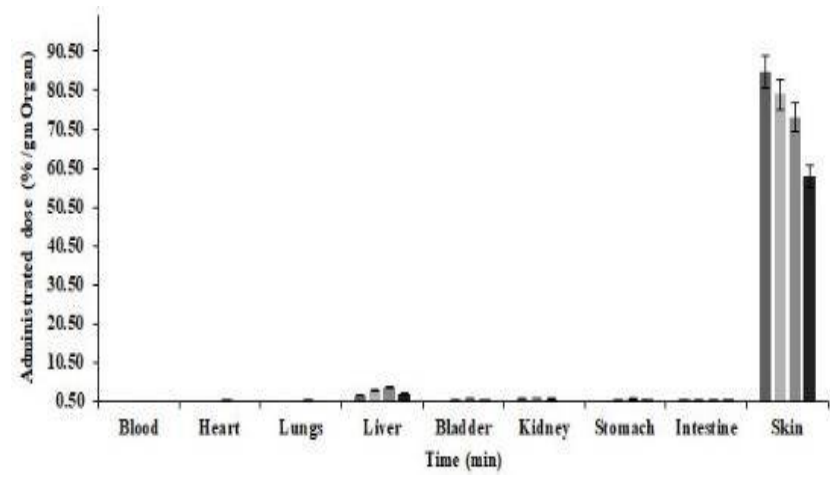

Figure 2: Biodistribution of radiolabeled 5-FU nanogel formulation. $\square-60 \mathrm{~min} ; \square-120 \mathrm{~min} ; \square-240 \mathrm{~min} ; \square$ 1440min

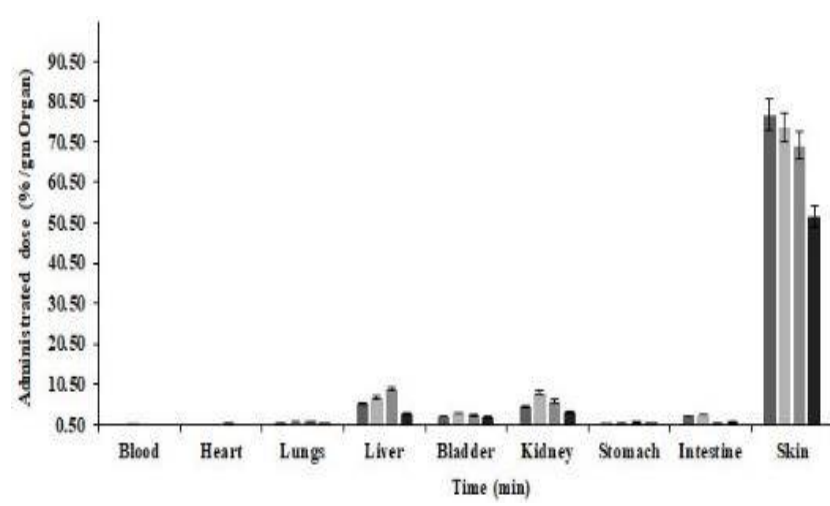

Figure 3: Biodistribution of radiolabeled 5-FU marketed formulation. $\square-60 \mathrm{~min} ; \square-120 \mathrm{~min} ; \square-240$ min; $\square-1440 \mathrm{~min}$ 
Table 3: Pharmacokinetics of the formulations in rabbits $(n=3)$

\begin{tabular}{|c|c|c|c|}
\hline Pharmacokinetic parameter & Unit & $\begin{array}{c}\text { Tc labelled 5-FU } \\
\text { nanogel }\end{array}$ & $\begin{array}{l}\text { Tc labelled 5-FU } \\
\text { marketed }\end{array}$ \\
\hline$T_{1 / 2}$ & $\mathrm{H}$ & 20.54 & 26.93 \\
\hline $\mathrm{T}_{\max }$ & $\mathrm{H}$ & 2.00 & 2.00 \\
\hline $\mathrm{C}_{\max }$ & $\mu \mathrm{g} / \mathrm{mL}$ & 34.20 & 39.69 \\
\hline$A \cup C_{0-t}$ & $\mu \mathrm{g} / \mathrm{mL}^{*} \mathrm{~h}$ & 313.76 & 583.69 \\
\hline$A \cup C_{0-\infty}$ & $\mu \mathrm{g} / \mathrm{mL}^{*} \mathrm{~h}$ & 550.01 & 1280.12 \\
\hline MRT $_{0-\infty}$ & $\mathrm{H}$ & 27.94 & 38.72 \\
\hline $\mathrm{CL}$ & $\mu \mathrm{g} /(\mu \mathrm{g} / \mathrm{mL}) / \mathrm{h}$ & 0.36 & 0.15 \\
\hline
\end{tabular}

\section{Pharmacokinetics}

Table 3 shows the pharmacokinetic parameters of radiolabelled 5-FU nanogel and marketed 5FU formulations in the blood.

\section{Gamma scintigraphy images}

Figure 4 shows scintigrams in the BALB/c mice at different time intervals $(2,4$ and $24 \mathrm{~h}$ ) postadministration of radiolabelled $99 \mathrm{~m}-\mathrm{Tc}-5-\mathrm{FU}$ nanogel and ${ }^{99 m}$-Tc-5-FU marketed formulations.

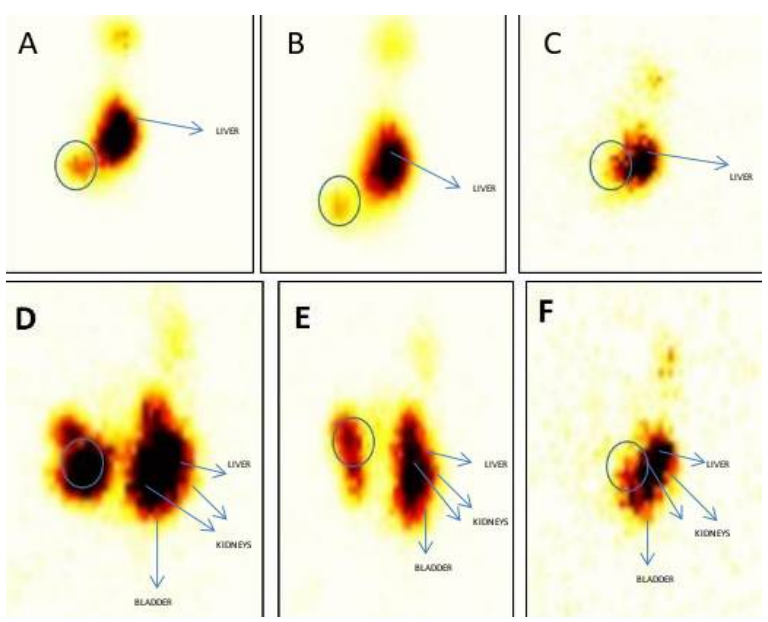

Figure 4: Scintigraphy scan of ${ }^{99 m-}$ Tc-labeled topical 5-FU nanogel formulation imaged at (A) $2 \mathrm{~h}$, (B) $4 \mathrm{~h}$, and $(C) 24 \mathrm{~h}$ post-topical administration on the dorsal side on the BALB/c mice. Scintigraphy scan of ${ }^{99 \mathrm{~m}-\mathrm{TC}} \mathrm{T}$ labeled topical 5-FU marketed formulation imaged at (D) $2 \mathrm{~h},(\mathrm{E}) 4 \mathrm{~h}$, and $(\mathrm{F}) 24 \mathrm{~h}$ post-topical administration on the dorsal side on the BALB/C mice. The oval circles denote points of application of the formulation

\section{DISCUSSION}

Studies by Rajagopalan et al revealed that the combination of 5-FU and GA-SA conjugate led to increased synergistic cytotoxicity against skin cancer A431 cell line, without any toxic effects in normal HaCaT cell line [12]. In GA-SA conjugate, stearylamine has a long hydrocarbon chain with 18 methylene units, and GA has antioxidant [19] and anticancer properties [12]. In the present study, GA-SA conjugate was used as an adjuvant for formulating 5-FU-loaded nanogel. In addition, sodium cholate was added as a stabilizing agent in the vesicular system, while carbopol 934 gel served as a cross-linked polyacrylic acid polymer for facilitating entrapment of the vesicles in the gel within the matrix space, thereby enhancing drug release over a long duration. Hence, the selected lipid nanocarrier-based vesicular system in gel form of 5-FU was suitable for topical administration on the skin. Viscosity (physicochemical parameter) was high in 5-FU nanogel, and $\mathrm{pH}$ was $6.5 \pm$ 0.01 , which is consistent with skin $\mathrm{pH}$. Thus, 5FU nanogel is suitable as a topical formulation. The entrapment efficiency (EE) of 5-FU was also improved. The usage of highly lipophilic GA-SA conjugate and sodium cholate enhances the fluidity of vesicle membranes, thereby increasing encapsulation efficiency. At $24 \mathrm{~h}$, the radiolabelling efficiency on 5-FU nanogel was more than $93 \%$, implying that the formulation was sufficiently stable.

The skin/blood ratio of 5-FU nanogel showed higher values for the formulated 5-FU than for the marketed 5-FU, indicating targeted delivery of the drug to the skin, thereby preventing drug entry into non-targeted locations in the body. Biodistribution studies showed that the amount of drug retained in the skin after topical administration of radiolabelled 5-FU nanogel seemed was considerably higher even after $24 \mathrm{~h}$, when compared to radiolabelled marketed 5-FU formulation. This provides further evidence of site-specific delivery of the drug. Therefore, 5-FU nanogel topical formulations have reduced systemic biodistribution and reduced toxicity.

The pharmacokinetic parameters of ${ }^{99 m}-\mathrm{Tc}-5-\mathrm{FU}$ nanogel in healthy New Zealand albino rabbits showed remarkably low maximum action $\left(\mathrm{C}_{\max }\right)$ in the plasma, low intensity (AUC) and low activity in blood, when compared to ${ }^{99 m}-$ Tc-5-FU marketed formulation (topical).

The scintigrams revealed that high radioactivity was seen at the point of application, and at 2, 4, and $24 \mathrm{~h}$ post-topical administration of ${ }^{99 m}-\mathrm{Tc}-5-$ FU nanogel. Mice treated topically with ${ }^{99 m}-$ Tc-5- 
FU marketed formulation had high accumulation in the liver, kidney and bladder, whereas for ${ }^{99 \mathrm{~m}}$. Tc-5-FU nanogel (topical), only small accumulation was found in the liver, which also confirmed the results from biodistribution studies.

\section{CONCLUSION}

The study reveals that topical 5-FU nanogel possess a higher activity on the skin than a commercial formulation of 5-FU. The GA-SA conjugate increases the localization of action and stability of the formulation. These findings confirm that encapsulation of $5-\mathrm{FU}$ in lipid vesicles within matrix spaces in a gel network system enhances the local action of the drug on the skin, reduces its systemic toxicity, and increases retention of drug in cutaneous epithelial cells. Thus, 1\% (w/w) 5-FU nanogel preparation possesses a therapeutic potential for the management of precancerous skin lesions.

\section{DECLARATIONS}

\section{Acknowledgement}

The authors would like to thank $\operatorname{Dr}$ Anil Kumar Mishra, Head, INMAS, New Delhi, India for providing the facilities for the radiolabelling studies.

\section{Conflict of interest}

No conflict of interest is associated with this work.

\section{Contribution of authors}

We declare that this work was done by the authors named in this article and all liabilities pertaining to claims relating to the content of this article will be borne by the authors.

\section{Open Access}

This is an Open Access article that uses a funding model which does not charge readers or their institutions for access and distributed under the terms of the Creative Commons Attribution License (http://creativecommons.org/licenses/by/ 4.0) and the Budapest Open Access Initiative (http://www.budapestopenaccessinitiative.org/rea d), which permit unrestricted use, distribution, and reproduction in any medium, provided the original work is properly credited.

\section{REFERENCES}

1. Youl PH, Janda M, Aitken JF, Del Mar CB, Whiteman DC, Baade PD. Body-site distribution of skin cancer, pre-malignant and common benign pigmented lesions excised in general practice. Br J Dermatol 2011; 165: 35-43.

2. Fu W, Cockerell CJ. The actinic (solar) keratosis. A 21st century perspective. Arch Dermatol 2003; 139: 66-70.

3. Roewert-Huber J, Stockfleth E, Kerl H. Pathology and pathobiology of actinic (solar) keratosis-an update. $\mathrm{Br}$ J Dermatol 2007; 157: 18-20.

4. Schreier H, Bouwstra J. Liposomes and niosomes as topical drug carriers: dermal and transdermal drug delivery. J Control Release. 1994; 30:1-15.

5. Cevc G, Blume G, Schatzlien A. Transfersomesmediated transepidermal delivery improves the regiospecificity and biological activity of corticosteroids in vivo. J Control Rel 1997; 45: 211-226.

6. Nishikawa T, Akiyoshi K, Sunamoto J. Macromolecular complexation between bovine serum albumin and the self-assembled hydrogel nanoparticle of hydrophobized polysaccharides. J Am Chem Soc 1996; 118: 61106115.

7. Kuroda K, Fujimoto $K$, Sunamoto J, Akiyoshi $K$. Hierarchical self-assembly of hydrophobically modified pullulan in water: Gelation by networks of nanoparticles. Langmuir 2002; 18: 3780-3786.

8. Goyal S, Sharma $P$, Ramchandani U, Shrivastava SK, Dubey PK. Novel anti-inflammatory topical herbal gels are containing Withania somnifera and boswellia serrata. Int J Pharm Biol Sci Arch 2011; 2:1087-1094.

9. Goncalves C, Paula Pereira, Miguel Gama. SelfAssembled Hydrogel Nanoparticles for Drug Delivery Applications. Materials 2010; 3: 1420-1460.

10. Ting $\mathrm{G}$, Chang $\mathrm{CH}$, Wang $\mathrm{HE}$. Cancer nanotargeted radiopharmaceuticals for tumor imaging and therapy, Anticancer Res 2009; 29: 4107-4118.

11. Krishnaiah YS, Satyanarayana S, Rama Prasad YV, Narasimha Rao S. Gamma scintigraphic studies on guar gum matrix tablets for colonic drug delivery in healthy human volunteers. J Control Rel 1998; 55: 245-252.

12. Rajagopalan $R$, Sanjay $K$, Jain, Piyush Trivedi. Synergistic anti-cancer activity of combined 5-fuorouracil and gallic acid-stearylamine conjugate in A431 human squamous carcinoma cell line. Trop J Pharm Res 2019; 18(3): 471-477.

13. Association for Assessment and Accreditation of Laboratory Animal Care International. [Internet] 2011. AAALAC International rules of accreditation. Section 2.d. Available at: http://www.aaalac.org/accreditation/ rules.cfm.

14. Vandana Gupta, Krishna Chuttani, Anil K. Mishra, Piyush Trivedi. Topical delivery of fluorescence (6-Cf) labeled and radiolabeled (99m-Tc) cisplatin and imiquimod by a dual drug delivery system. J. Label Compd. Radiopharm 2014; 57: 425-433. 
15. Vyas TK, Babbar AK, Sharma RK, Singh S, Misra AJ. Intranasal mucoadhesive microemulsions of clonazepam: preliminary studies on brain targeting. $J$ Pharm Sci 2006; 95: 570-579.

16. Saha GB. In Physics and Radiobiology of Nuclear Medicine (Eds: G. B. Shah), Springer, New York, 1993 pp. 100-106.

17. Brijeshkunvar J Mishra, Ankur Kaul, Piyush Trivedi. LCysteine conjugated poly L-lactide nanoparticles containing 5-fluorouracil: formulation, characterization, release and uptake by tissues in vivo. Drug Deliv 2014; 1-9.

18. Kumar M, Misra A, Babar AK, Mishra AK, Mishra $P$, Pathak K. Intranasal nanoemulsion based brain targeting drug delivery system of risperidone. Int $J$ Pharm 2008; 358: 285-291.

19. Da Rosa CG, Borges CD, Zambiazi RC, Nunes MR, Benvenutti EV, Da Luz SR, D’Avila RF Rutz JF. Microencapsulation of gallic acid in chitosan, $\beta$ cyclodextrin and xanthan. Industrial Crops Products 2013; 46: 138-146. 